\title{
Urinary Orosomucoid ( $\alpha$-1-Acid Glycoprotein) As A Single Potential Biomarker Through PET Assay for Diagnosis of Early Onset Sepsis in Neonates: A Review
}

\author{
Alfiani Zukhruful Fitri Rifa'i', Hanifah Nabilah', \\ Idznika Nurannisa Wibowo', Reny I'tishom ${ }^{2 *}$ \\ ${ }^{1}$ Medical Program, Faculty of Medicine Universitas Airlangga, \\ 60132, Surabaya, East Java, Indonesia \\ 2Department of Biomedical Science, Faculty of Medicine Universitas Airlangga, \\ 60132, Surabaya, East Java, Indonesia
}

*Corresponding author details: Reny I'tishom; ritishom@fk.unair.ac.id

\begin{abstract}
Neonatal sepsis is a condition in which bacteria are present in an infant's sterile body fluids. It is considered one of the most common causes of infant death, with nearly one million deaths per birthday and approximately 2 million deaths in the first week of life. To aid in the early diagnosis of neonatal sepsis, a potential new biomarker for early neonatal sepsis called orosomucoid (ORM) or $\alpha 1$-glycoprotein ( $\alpha 1$ AGP) in urine is being evaluated because of its greater accuracy than current diagnostic tools. Combined with particle turbidity analysis (PET), neonatal sepsis can be diagnosed in an immediate, sensitive, specific and non-invasive manner. The early local increase in urinary ORM in sepsis suggests that it could be a new promising marker of sepsis and an important part of routine laboratory and clinical practice.
\end{abstract}

Keywords: Biomarker; orosomucoid; u-ORM; -1-acid glycoprotein; $\alpha$-1AGP; sepsis; particle-enhanced turbidimetric test; neonates.

\section{INTRODUCTION}

Neonatal sepsis is the most common causes of morbidity and mortality in term and preterm infants [1]. It has been defined as the presence of bacteria in sterile body fluids: blood, urine, cerebrospinal fluid, peritoneum, and pleural fluid $[1,2]$. Thus, although there is no universal definition of neonatal sepsis [3], when pathogenic bacteria enter the bloodstream, they can cause an overwhelming infection (sepsis) or be localized primarily in the lungs (pneumonia) or meninges (meningitis). 4].

The World Health Organization (WHO) estimates that 45\% of deaths in under-five years occurring during their first month of life [5]. A recently published study reported prematurity and neonatal sepsis as the major cause of infant mortality $[6,7,8]$. Almost one million deaths occur on the day of birth and close to two million died in the first week of life. Incidence of neonatal sepsis varies from 1$4 / 1000$ live births in developed countries to 10-50/1000 live births in developing countries [9].

Neonatal sepsis is divided into early-onset sepsis (EOS) and late-onset sepsis (LOS) depending on the time of onset after birth. The initial onset of sepsis begins before 72 hours after birth, and the pathogen predominates in the mother's genitals or the birth site. Late sepsis is caused by microorganisms from the environment outside the home or hospital [10]. EOS is mainly caused by perinatally acquired bacteria (70\%) group B streptococci and Escherichia coli [11]. In some studies, E. Escherichia coli, 1 and GBS, which have a higher risk of thrombocytopenia and first-day death, are primarily responsible for meningitis in infants with severe neurological impairment [12].
The mortality rate in EOS patients was estimated to be $38 \%$ [1].

Accurate and timely diagnosis of early onset neonatal sepsis remains challenging for clinicians and laboratory [13], due to variable and non-specific clinical signs [14]. Clinical symptoms vary from fever, cyanosis, apnea, hypotonia, seizures, anorexia, hepatomegaly, and jaundice [15]. So, it is difficult to differentiate from those of noninfectious etiologies [1]. Biomarkers for diagnosis of neonatal sepsis have been discovered that helps in the early diagnosis of neonatal sepsis, before the onset of clinical manifestations so that early treatment of sepsis can be started and neonate can be properly managed [14]. Although several novel diagnostic markers (C-reactive protein (CRP), serum amyloid A, Procalcitonin (PCT), Neutrophil CD64, Presepsin, Cytokines, Metabolomics) have been discovered to detect the onset of disease, at this moment, there is no proper diagnostic tool developed that can accurately diagnose sepsis [15].

Due to their limitations (sensitivity, specitivity, etc), a new potential biomarker for EOS in neonatal called orosomucoid (ORM) or $\alpha$-1-acid glycoprotein ( $\alpha$-1AGP) is evaluated, as it has a function in modulating the activity of the immune system during the acute phase reaction [16]. High levels of $\alpha 1$ AGP were found in $85 \%$ of infants with severe bacterial infection. In $26 \%$ of sick infants without infection, $\alpha 1 \mathrm{AGP}$ levels increased slightly and then decreased rapidly. Serum $\alpha 1 \mathrm{AGP}$ concentrations in bacterial infection were consistent with the clinical course [17]. Therefore, the concentration of $\alpha 1$ AGP was a useful parameter for the diagnosis and monitoring of bacterial infection in newborns [18]. 
The aim of the writing of this literature review is to evaluate and determine whether orosomucoid (ORM) or $\alpha$ 1-acid glycoprotein ( $\alpha-1$ AGP) in urine has the possibility of diagnostic ability for the early recognition of early onset neonatal sepsis in full-term neonates.

\section{METHODS}

Search strategies for this literature review were combined by multiple sources, such as NCBI, PubMed Central, MEDLINE, and Google Scholar online instruments. Keywords used are $\alpha$ 1-acid glycoprotein, neonates, diagnosis, early onset sepsis, and urinary orosomucoid, with filters used are 10 years from publication date and human species only. There are 62 literatures used based on the relevance and reliability, which are systematic reviews, meta-analysis and randomized control trials (RCTs). Articles were included if they met the following criteria: (1) original research, (2) population-based (selecting the entire population or using probability-based sampling methods), and (3) reports a prevalence or incidence of sepsis. Level of evidence are determined based on classification under license of Oxford Centre for Evidence-based Medicine Level of Evidence [19].

\section{RESULTS AND DISCUSSION}

(1) Early Onset Neonatal Sepsis and the Urgencies in Developing Countries with Holistic Approach

The global burden of morbidity because of neonatal infection was estimated at 3\% of all Disability Adjusted Life Years [20], but this estimation excludes long-term morbidity. Every year 2.6 million neonates die; three fourths of these deaths occur in the first week of life, and almost all (99\%) in low- and middle-income countries [21]. Neonatal sepsis is the third leading cause of neonatal mortality, below prematurity and intrapartum-associated complications (or birth asphyxia). It is responsible for $13 \%$ of all neonatal mortality, and $42 \%$ of deaths withinside the first week of life [22]. Developing countries lack surveillance system, and a high proportion of newborns in these countries die at home before they are registered. Consequently, neonatal sepsis is probably to be underreported in these countries, suggesting that its impact on mortality may be even higher [23].

Neonatal sepsis can be called a clinical syndrome consisting of circulatory disorders in neonates. The virulent bacteria reach into the bloodstream, which results into the profuse microbial infection causing an ineffective host response [24]. Studies have shown that many chemicals are involved in the pathophysiological process of sepsis. The original model of sepsis was the immune response to endotoxin, a lipopolysaccharide (LPS) found in the cell walls of Gram-negative bacteria. Endotoxins are excellent example of a pathogenassociated molecular pattern (PAMP). Innate immune cells such as macrophages have receptors that recognize different types of PAMPs [25]. Toll-like receptors (TLRs) and lectin receptors on the cell surface recognize a variety of bacterial substances in the extracellular space. When engaged by bacterial ligands, these receptors stimulate macrophages to produce tumor necrosis factor (TNF), interleukin-1b (IL-1b) and IL-6. These three proinflammatory cytokines induce the systemic inflammatory response which is characteristic of early sepsis, and for many years physicians believed that sepsis essentially represented an unusually robust reaction on the part of the innate immune system to a bacterial infection [26].

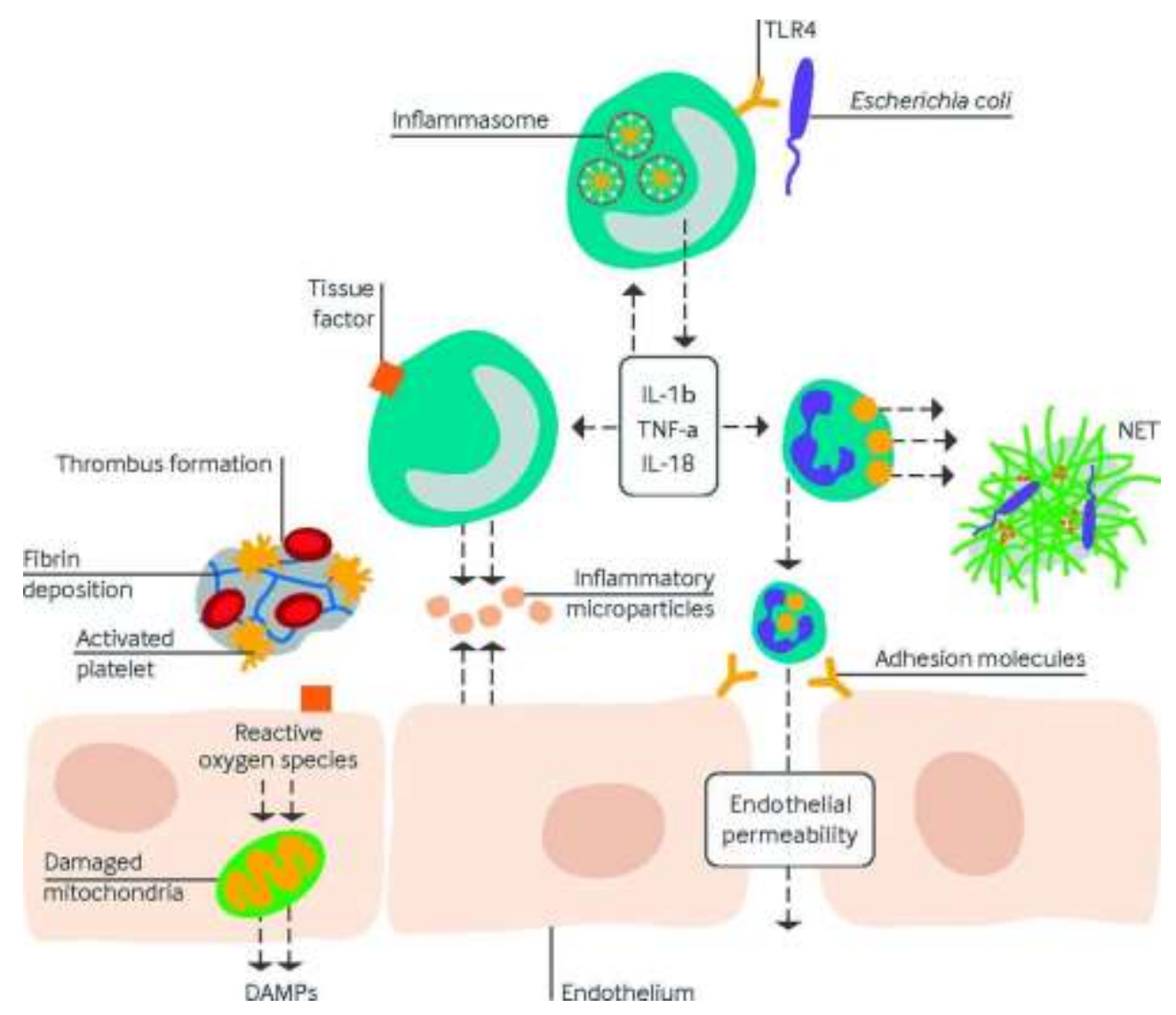

FIGURE 1: Pathophysiologic processes involved in sepsis [62]. DAMPs= damage associated molecular patterns; IL= interleukin; TLR4= Toll-like receptor 4; TNF- $\alpha=$ tumor necrosis factor $\alpha$ 
In developing countries, clinically diagnosed sepsis occurs in 49-170 per 1000 live births, culture-confirmed sepsis in 16 per 1000 live births and neonatal meningitis in 0.8-6.1 per 1000 live births [23]. Infants with neonatal infections are more likely to have poor neurodevelopmental outcomes at follow up, including cerebral palsy, lower mental and psychomotor development index scores, visual impairment and impaired growth $[27,28]$. Early diagnosis and treatment are important for progressively improving outcomes. With early diagnosis and active supportive therapy, most neonatal sepsis can be saved [29].

Prescribing antibiotics to newborns shows high risk factors associated with sepsis. Extended antibiotic therapy is consistent with associated risk factors for increased antibiotic resistance [23]. These other features can be seen in different neonatal conditions, making neonatal sepsis difficult to diagnose and lead to overtreatment. The late onset of clinical signs and symptoms sometimes leads to a transition of the neonates from the compensatory to refractory phase, which increases mortality [30].

Signs of EOS in full-term infants usually appear within the first 6 hours of life and most often appear during the first 24 hours of life. Most infants will present with respiratory distress, which can masquerade as other diagnoses such as congenital heart disease, respiratory distress syndrome (RDS), pneumothorax, transitory tachypnea of new-borns, congenital diaphragmatic hernia, and other congenital masses in the chest [31]. Most cases (80\% to $90 \%$ ) of EOS will present in the first $24 \mathrm{~h}$ to $48 \mathrm{~h}$ of life [32]. The most common cause of early-onset sepsis is Group B Streptococcus (GBS), isolated in half of episodes, followed by Escherichia coli, isolated in one-fourth of episodes [33]. The remaining cases of early-onset sepsis are caused by Staphylococcus aureus, Coagulase-negative Staphylococcus (CoNS), Listeria monocytogenes and other gram-negative bacteria $[34,35]$. Some studies suggest that infants infected with E. coli have a more aggressive course and a higher risk of thrombocytopenia and first-day death [36], and GBS is primarily responsible for meningitis in infants with severe neurological disorders [37]. Mortality was estimated to be $38 \%$ among patients with EOS [36].

\section{(2) Current Diagnostic Guidelines Regarding Neonatal Sepsis Has Limitations and Drawbacks}

One of the main challenges in treating neonatal sepsis is making an accurate diagnosis. It has been found that biomarkers for the diagnosis of neonatal sepsis can start early treatment of sepsis and ensure proper management of the newborn by helping to diagnose neonatal sepsis at an early stage before clinical manifestations appear [38]. Unlike older patients, newborns have very subtle symptoms, and many conditions resemble neonatal sepsis [39]. Blood cultures are also insensitive due to certain characteristics of the neonatal population. The frequency of positivity is low and depends on the volume of blood vaccinated, prenatal antibiotic use, bacteremia level, and laboratory dose $[27,39]$. So far, many markers for the early diagnosis of sepsis $[40,41]$, especially C-reactive protein (CRP) and procalcitonin (PCT) have been proposed. CRP is an acute-phase protein found in the blood and is produced in the liver due to infection or tissue damage. PCT is a 116 amino acid peptide that is involved in calcium homeostasis, both of which are widely used as useful markers for neonatal diagnosis. sepsis [42]. However, the specificity and value of CRP and PCT are still questionable. Therefore, there is a constant need to find the best biomarkers of sepsis [43].

The concentration of CRP increases rather slowly in the early stages of the inflammatory response to the pathogen and the sensitivity is insufficient [44].
One value of CRP (C-reactive protein) shows an unacceptably low sensitivity, especially in the early stages of infection [27]. Elevated CRP levels may also be more difficult to interpret as their epidemiology may be influenced by factors such as premature amnion rupture (PROM), maternal fever, pregnancy-induced hypertension, prenatal steroid use, fetal distress, and gestational age. [45]. Several Iranian researchers have compared CRP to specific inflammatory mediators as a parameter for early diagnosis of neonatal sepsis. CRP $12 \mathrm{mg} / \mathrm{L}$ was identified as the most appropriate cutoff value using a receiver performance curve (ROC), at which the test was 45\% sensitive, 95\% specific, 30\% PPV and 30\% NPV [46].

The specificity and sensitivity of procalcitonin (PCT) are also relatively low. Its levels increase faster than CRP and may be more useful for EOS detection, but may also increase for non-infectious causes such as dyspnea, trauma, major and cardiac surgery, and physiologically within the first 24 hours after birth [44]. In early-onset sepsis, the sensitivity is $70-77 \%$, while values obtained immediately after birth have a sensitivity of only $49 \%$ [47]. However, like CRP, procalcitonin greatly depends on the date of birth and gestational period, so these factors should be considered when interpreting their values [48].

Blood cultures are still used to diagnose sepsis, but this method is too slow and limited to false-negative results. Although there are many biomarkers of sepsis evaluated for early diagnosis of neonatal sepsis, there is no single ideal biomarker today, although new biomarkers are becoming more complex and specific in clinical applications [40]. Therefore, the $\alpha 1$ Acid glycoprotein was found to be a promising marker [49].

\section{(3) Urinary Orosomucoid (U-ORM) Coupled with Particle Enhanced Turbidimetric Assay as Neonatal Sepsis Diagnosing Tool}

Orosomucoid, or $\alpha$-1-Acid Glycoprotein, is an acute phase protein weighted around $44 \mathrm{kDA}$ containing 183 amino acid residues and $5 \mathrm{~N}$-linked oligosaccharides.50 Unlike other acute phase proteins, ORM is mediated by both cytokines (IL-1, IL-6, TNF- $\alpha$ ) and glucocorticoids [50]. ORM in sepsis attenuates the inflammatory response by binding to L-selectin, reduces neutrophil migration and roll-off, granulocyte efflux and T-cell endothelial or platelet attraction to sites of inflammation, as well as nitroxide with glycans Control the dependency path. moieties [51].

Normal concentrations of orosomucoids in human serum range from $0.5-1.2 \mathrm{~g} / \mathrm{l}$ and may be elevated in acute and chronic inflammatory diseases [52]. During the acute phase response, serum ORMs (seORMs produced in hepatocytes and peripheral tissues) may increase 2-7-fold [53]. Precipitation formed by the antiviral $\alpha 1 \mathrm{AGP}$ was measured using a spectrophotometer at $340 \mathrm{~nm}$ after intravenous samples of $1 \mathrm{ml}$ were taken from neonates during SEORM. For the suspected group at the $\alpha 1$ AGP threshold level of $39 \mathrm{mg} / \mathrm{dL}$, the statistical results indicate the need for continuous and invasive measurements with $60 \%$ sensitivity and $90 \%$ specificity [54].

ORM can also be detected in urine at concentrations much lower than serum [55]. In contrast, urine ORM may be a more sensitive marker of inflammation than serum ORM, which only doubles in size, in contrast to a 200 -fold increase in sepsis uORM with sensitivity and specificity of $94.7 \%$ and $90.0 \%$, respectively [56]. uORM appears to be a more sensitive marker of sepsis than seORM (Figure 2), providing clinically relevant information for monitoring inflammatory activation in real time in a non-invasive manner [57]. 


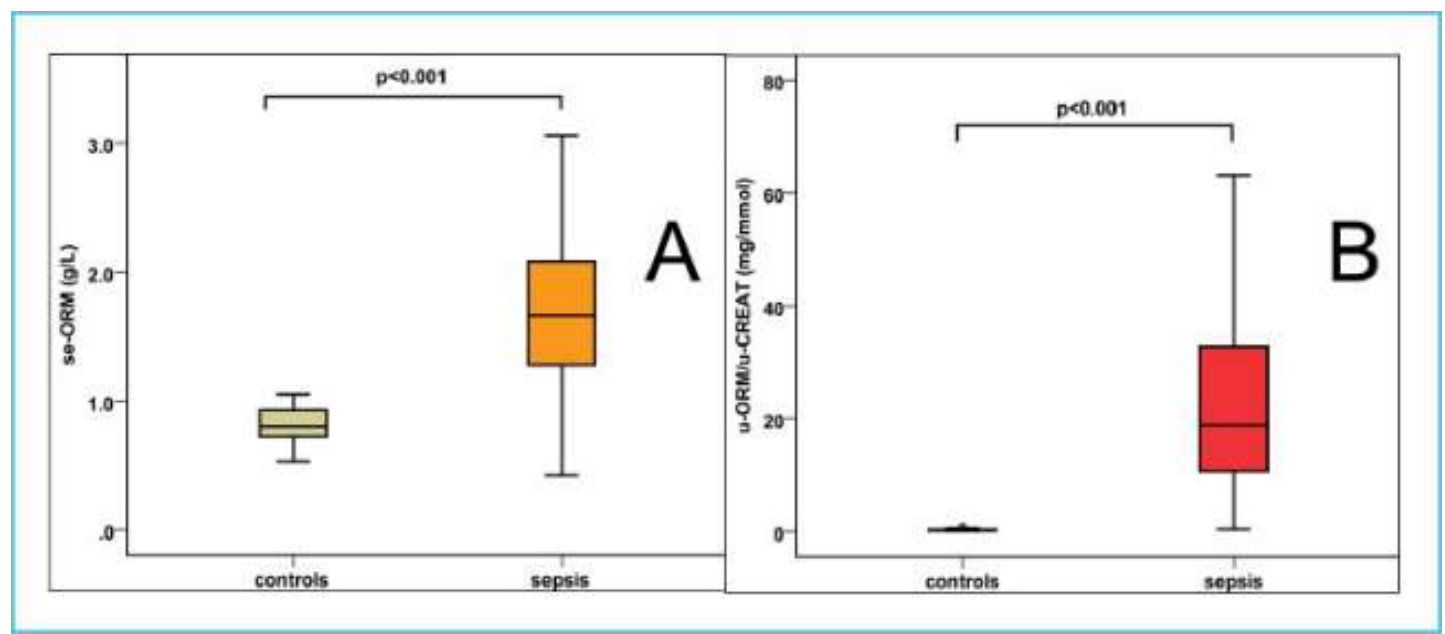

FIGURE 2: Serum orosomucoid (A) and urinary orosomucoid (B) levels in sepsis. Urinary orosomucoid levels are referred to urinary creatinine and expressed in $\mathrm{mg} / \mathrm{mmol}[58]$.

The u-ORM/total protein proportion (u-ORM/u-TP) also showed an elevation among critically ill patients: in controls the u-ORM accounted for only $1.6 \%-4.0 \%$ of urinary proteins, while in sepsis $\mathrm{u}-\mathrm{ORM} / \mathrm{u}$-TP ranged from 10.2 to $34.0 \%$ [58]. So far Kustan et al. published increased $\mathrm{u}$-ORM excretion in sepsis, monitoring septic patients for a longer time period, and we found an early rise of u-ORM/ $\mathrm{u}$-CREAT levels in sepsis which did not change during our 5-day follow-up study. This phenomenon can be explained by the ongoing severe inflammatory condition and also by the relatively long, 5 days half-life of ORM [58]. It was reported that AGP reaches its maximum concentration 48 hours after the onset of infection and continues to increase for a long time (120-144 hours after onset), thus, we expected that serum AGP was likely to yield a more accurate estimate of the prevalence of inflammation [59]. Increased uORM excretion also did not indicate renal dysfunction [60].
Another advantage of this biomarker is that there is no correlation with age and no difference was found according to gender and urine collection type [56]. Therefore, it can be used in the neonatal population. There are several other methods for determining uORM (Western blotting, radioimmunoassay, ELISA), but not all of these tests are suitable for routine work. Western blotting has a lower uORM concentration compared to PET (particle-enhanced turbidity measurement) analysis. Therefore, particle-enhanced turbidity measurement (PET) analysis is used to determine the uORM. This new turbidity measurement method is designed to be fast, sensitive and accurate, making it ideal for routine uORM measurements. The test takes only 10 minutes [55]. Due to its unusually low LOQ $(0.08 \mathrm{mg} / \mathrm{L})$ and good functional sensitivity $(0.03 \mathrm{mg} / \mathrm{L})$, the PET test can quantitatively determine uORM in all healthy individuals and even in patients with systemic inflammatory disease after appropriate dilution [56].

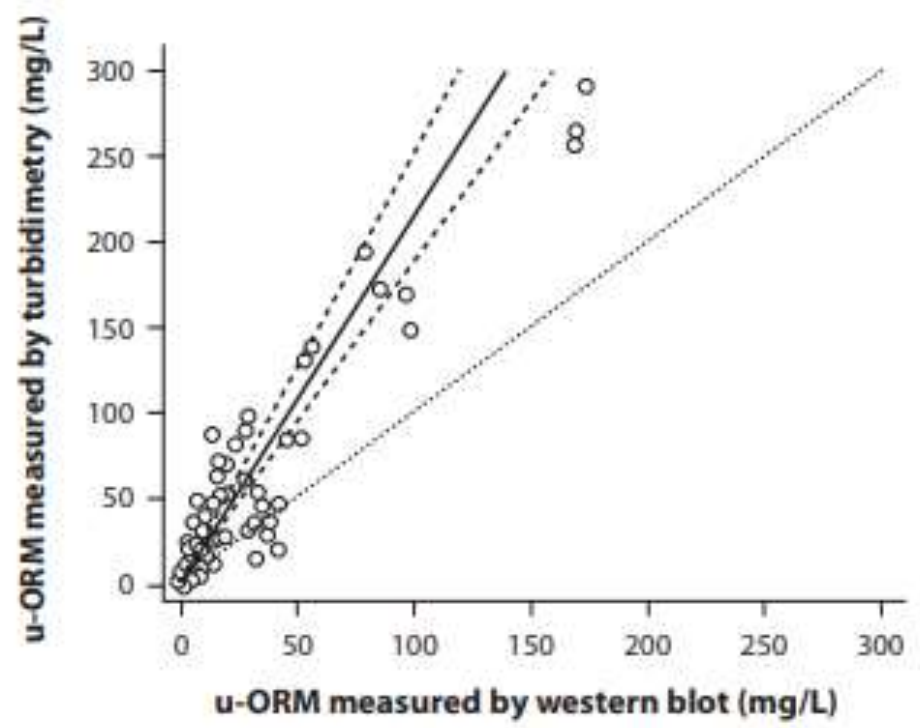

FIGURE 3: Comparison of quantitative western blotting and the new automated turbidimetric assay for u-ORM measurement [56]. Solid line - regression line. Dashed lines - 95\% CI for the regression line. Dotted line - identity line $(x=y)$. 
Considering that urine orosomucoid measurement time is less than 10 minutes, it can be a potential biomarker for sepsis compared to 30 minutes for other biomarkers such as CRP [61]. This method is accurate enough to measure orosomucoid in urine. Validation of a sensitive, accurate and fully automated particle turbidity measurement (PET) assay for urine orosomucoids that provides early and valuable information on inflammatory disease [55].

\section{CONCLUSION}

Measurement of $\alpha 1$-glycoprotein (AGP) or orosomucoid (ORM) in urine may provide new opportunities for early recognition of infection-induced systemic inflammation. As a biological fluid, urine has great potential for future use in laboratory research in many other clinical and diagnostic applications, as it is a unique sample with many collection-related advantages. It can be used for noninvasive methods and sampling. The procedure is painless. In addition, uORM has higher sensitivity and specificity than other biomarkers of neonatal sepsis. Combined with the particle-enhanced turbidimetry test (PET), neonatal sepsis can be diagnosed in an immediate, sensitive, specific, and non-invasive manner. The duo is a particularly useful tool for national and international programs for the diagnosis of infectious diseases, including sepsis. This is because it can be easily and non-invasively sampled from large populations, especially in newborns. In addition, larger multicenter studies and AGP studies should be conducted to obtain more scientific evidence.

\section{ACKNOWLEDGEMENTS}

The author would like to thank all those who helped in writing this piece of literature.

\section{REFERENCES}

[1] Camacho-Gonzalez A, Spearman PW, Stoll BJ. Neonatal infectious diseases: evaluation of neonatal sepsis. Pediatr Clin North Am. 2013; 60:367-389.

[2] Sharma, D., Farahbakhsh, N., Shastri, S., \& Sharma, P. Biomarkers for diagnosis of neonatal sepsis: a literature review. The Journal of Maternal-Fetal \& Neonatal Medicine. 2017; 31(12), 1646-1659.

[3] Wynn, J. L. Defining neonatal sepsis. Curr. Opin. Pediatr. 2016; 28, 135-140

[4] Paolucci M, Landini MP and Sambri V. How can the microbiologist help in diagnosing neonatal sepsis? International journal of Pediatrics; article ID 120139, 14 pages, 2012.

[5] Kari A Simonsen, Ann L Anderson, Shirley. FDelair and H. Dele Davies. Early onset sepsis. Clin Microbiol Rev. 2014; 27(1):21-47.

[6] Lozano R, Naghavi M, Foreman K, et al. Global and regional mortality from 235 causes of death for 20 age groups in 1990 and 2010: a systematic analysis for the Global Burden of Disease Study 2010. Lancet. 2012;380:2095-2128.

[7] Wang H, Liddell CA, Coates MM, et al. Global, regional, and national levels of neonatal, infant, and under-5 mortality during 1990-2013: a systematic analysis for the Global Burden of Disease Study 2013. Lancet. 2014;384:957-979

[8] Rajaratnam JK, Marcus JR, Flaxman AD, et al. Neonatal, postneonatal, childhood, and under-5 mortality for 187 countries, 1970-2010: a systematic analysis of progress towards Millennium Development Goal 4. Lancet. 2010;375:1988-2008.
[9] Made IK. Incidence and factors associated with mortality of neonatal sepsis. Pediatrindones J. 2013; vol.51.

[10] Jones AR, Kuschel C, Jacobs S and Doyle LW. Reduction in late onset sepsis on relocating a neonatal intensive care nursery. Journal of pediatrics and child health. 2012; vol.48, Issue 10, 891-895.

[11] Vergnano S, Menson E, Kennea N, et al. Neonatal infections in England: the NeonIN surveillance network. Arch Dis Child Fetal Neonatal Ed 2011;96:F9-14.

[12] F. Levent, et al., Early outcomes of group B streptococcal meningitis in the 21st century, Pediatr. Infect. Dis. J. 29 (11) .2010. 1009e1012. - R. Libster, et al., Long-term outcomes of group B streptococcal meningitis, Pediatrics 130 (1) .2012. e8e15.

[13] Khair KB, Rahman MA, Sultan T, Roy CK, Rahman MQ and Ahmed AN. Early diagnosis of neonatal septicemia by hematological scoring system, Creactive protein and serum haptoglobin. Mymensingh MED J. 2012; 21(1):85-92.

[14] Hedegaard, S. S., Wisborg, K., \& Hvas, A.-M.. Diagnostic utility of biomarkers for neonatal sepsis a systematic review. Infectious Diseases. 2014; 47(3), 117-124.

[15] Shah, B. A., Padbury, J. F. Neonatal Sepsis. Virulence. 2013; 5(1), 170-178.

[16] Tzialla, C., Achille, C., Bollani, L., Stronati, M., Borghesi, A., \& Manzoni, P. (2018). New Diagnostic Possibilities for Neonatal Sepsis. American Journal of Perinatology, 35(06), 575-577.

[17] Smith KD, Behan J, Mattews-Smith G and Magliocco AM. Alpha-1-acid glycoprotein as a potential biomarker for breast cancer. Genetics and molecular biology. 2012; 9:201-222.

[18] Sann L, Bienvenu J, Lahet C, Divry P and Cotte J. Serum orosomucoid concentration in newborn infants. Clin Chem;27(5):721-726, 2009.

[19] Jeremy, H. et al. 2011. "The Oxford. Levels of Evidence". Oxford Centre for Evidence-Based Medicine.

[20] Murray CJ, Vos T, Lozano R, et al. Disability-adjusted life years (DALYs) for 291 diseases and injuries in 21 regions, 1990-2010: a systematic analysis for the Global Burden of Disease Study 2010. Lancet 2013; 380:2197- 2223 .

[21] Wang H, Liddell CA, Coates MM, et al. Global, regional, and national levels of neonatal, infant, and under-5 mortality during 1990-2013: a systematic analysis for the Global Burden of Disease Study 2013. Lancet 2014; 384:957-79.

[22] Liu L, Johnson HL, Cousens S, et al. Global, regional, and national causes of child mortality: an updated systematic analysis for 2010 with time trends since 2000. Lancet 2012; 379:2151-61.

[23] Thaver D, Zaidi AKM. Burden of neonatal infections in developing countries: a review of evidence from community based studies. Pediatr Infect Dis J 2009;28(1 Suppl):S3-9 
[24] J.K. Carvalho, et al., Prediction of sepsis-related outcomes in neonates through systematic genotyping of polymorphisms in genes for innate immunity and inflammation: a narrative review and critical perspective, Sao Paulo Med. J. 131 (5) (2013) $338 \mathrm{e} 350$.

[25] Kumar H, Kawai T, Akira S. Pathogen recognition by the innate immune system. (2011). Int Rev Immunol;30:16-34.

[26] Faix, J. D. (2013). Biomarkers of sepsis. Critical Reviews in Clinical Laboratory Sciences, 50(1), 23-36.

[27] A. Zea-Vera, T.J. Ochoa, Challenges in the diagnosis and management of neonatal sepsis, J. Trop. Pediatr. 61 (1). 2015. 1e13.

[28] Stephens BE, Vohr BR. Neurodevelopmental outcome of the premature infant. Pediatr Clin North Am 2009;56: 631-46.

[29] I. M. Stefanovic, "Neonatal sepsis," Biochemia Medica (Zagreb), vol. 21, no. 3, pp. 276-281, 2011.

[30] Sharma, D., Farahbakhsh, N., Shastri, S., \& Sharma, P. 2017. Biomarkers for diagnosis of neonatal sepsis: a literature review. The Journal of Maternal-Fetal \& Neonatal Medicine, 31(12), 1646-1659

[31] Simonsen, K. A., Anderson-Berry, A. L., Delair, S. F., \& Davies, H. D. 2014. Early-Onset Neonatal Sepsis. Clinical Microbiology Reviews, 27(1), 21-47.

[32] Polin RA, Committee on Fetus and Newborn. 2012. Management of neonates with suspected or proven early-onset bacterial sepsis. Pediatrics 129:1006 1015

[33] Downie L, Armiento R, Subhi R, et al. Community acquired neonatal and infant sepsis in developing countries: efficacy of WHO's currently recommended antibiotics - systematic review and meta-analysis. Arch Dis Child 2012; 98:146-154.

[34] Vergnano S, Menson E, Kennea N, et al. Neonatal infections in England: the NeonIN surveillance network. Arch Dis Child Fetal Neonatal Ed 2011;96:F9-14.

[35] Stoll BJ, Hansen NI, Sa'nchez PJ, et al. Early onset neonatal sepsis: the burden of group B Streptococcal and E. coli disease continues. Pediatrics 2011;127: 817-26.

[36] Camacho-Gonzalez A, Spearman PW, Stoll BJ. Neonatal infectious diseases: evaluation of neonatal sepsis. Pediatr Clin North Am 2013;60:367-89.

[37] F. Levent, et al., Early outcomes of group B streptococcal meningitis in the 21st century, Pediatr. Infect. Dis. J. 29 (11) .2010. 1009e1012. - R. Libster, et al., Long-term outcomes of group B streptococcal meningitis, Pediatrics 130 (1) .2012. e8e15.

[38] Hedegaard SS, Wisborg K, Hvas A-M. Diagnostic utility of biomarkers for neonatal sepsis-a systematic review. Infect Dis (Lond). 2015;47:117-124.

[39] Camacho-Gonzalez A, Spearman PW, Stoll BJ. Neonatal infectious diseases: evaluation of neonatal sepsis. Pediatr Clin North Am 2013;60:367-89.
[40] Tzialla, C., Achille, C., Bollani, L., Stronati, M., Borghesi, A., \& Manzoni, P. (2018). New Diagnostic Possibilities for Neonatal Sepsis. American Journal of Perinatology, 35(06), 575-577

[41] C. Pierrakos and J.-L. Vincent, "Sepsis biomarkers: a review," Critical Care, vol. 14, no. 1, article R15, 2010.

[42] B. S. Naher, M. A. Mannan, K. Noor, and M. Shahiddullah, "Role of serum procalcitonin and Creactive protein in the diagnosis of neonatal sepsis," Bangladesh Medical Research Council Bulletin, vol. 37, no. 2, pp. 40-46, 2011.

[43] Yuan, H., Huang, J., Lv, B., Yan, W., Hu, G., Wang, J., \& Shen, B. (2013). Diagnosis Value of the Serum Amyloid A Test in Neonatal Sepsis: A Meta-Analysis. BioMed Research International, 2013, 1-9. doi:10.1155/2013/520294

[44] Decembrino, L., De Amici, M., Pozzi, M., De Silvestri, A., \& Stronati, M. (2015). Serum Calprotectin: A Potential Biomarker for Neonatal Sepsis. Journal of Immunology Research, 2015, 1-4.

[45] Hofer N, Müller W, Resch B. Non-infectious conditions and gestational age influence $\mathrm{C}$-reactive protein values in newborns during the first 3 days of life. Clin Chem Lab Med 2011;49:297-302.

[46] Minoo Adib, Zahara Bashshiani, Fakhri Navaei, Fereshteh Saheb Fosoul, Salomeh Fiouladi and Hamidreza Kazemzadeh. Procalcitonin: A reliable marker for the diagnosis of neonatal sepsis. Iran J Basic Med Sci; vol 15,no 2:777-783, 201

[47] Vouloumanou EK, Plessa E, Karageorgopoulos DE, et al. Serum procalcitonin as a diagnostic marker for neonatal sepsis: a systematic review and metaanalysis. Intensive Care Med 2011;37:747-62.

[48] Chiesa C, Natale F, Pascone R, et al. C reactive protein and procalcitonin: reference intervals for preterm and term newborns during the early neonatal period. Clin Chim Acta 2011;412:1053-9.

[49] Ipek IO, Saracoglu M and Bozaykut A. Alpha 1-acid glycoprotein for the early diagnosis of neonatal sepsis. J Matern Fetal Neonatal Med; 23(7):617-21, 2014

[50] Taguchi K, Nishi K, Giam Chuang V, Maruyama T, Otagiri M. Molecular Aspects of Human Alpha-1 Acid Glycoprotein - Structure and Function. Acute Phase Proteins. 2013;

[51] Hsiao S, Lai Y, Kung C, Tsai N, Su C, Huang C et al. $\alpha-1$ Acid Glycoprotein Concentration as an Outcome Predictor in Adult Patients with Sepsis. BioMed Research International. 2019;2019:1-9.

[52] Ceciliani F, Pocacqua V. The acute phase protein alpha1-acid glycoprotein: a model for altered glycosylation during diseases. Curr Protein Pept Sci. 2007;8(1):91-108

[53] Ceciliani F, Lecchi C. The Immune Functions of $\alpha 1$ Acid Glycoprotein. Current Protein \& Peptide Science. 2019;20(6):505-524.

[54] Wahab A, Elsharkawy S, AbdAllah N, Elkasaby A. (2016). Alpha 1 Acid Glycoprotein as a Marker for Diagnosis of Early Onset Neonatal Sepsis in Fullterm Neonates. Journal of American Science, 12(7):139-144. 
[55] Kustán, P., Szirmay, B., Horváth-Szalai, Z., Ludány, A., Lakatos, Á., Mühl, D., ... Kőszegi, T. (2016). Urinary orosomucoid: validation of an automated immune turbidimetric test and its possible clinical use. Biochemia Medica, 421-430

[56] Kustán P, Szirmay B, Mühl D, Ludány A. 2015.Human orosomucoid in the clinical laboratory. In: Kőszegi T, ed. Techniques with applicability in medical practice. Saarbrücken: LAP Lambert Academic Publishing; P.101-20

[57] Kőszegi T. Advances in the Diagnosis of Sepsis. The Journal of the International Federation of Clinical Chemistry and Laboratory Medicine. 2017;28(2):99103.

[58] Kustán, P., Szirmay, B., Horváth-Szalai, Z., Ludány, A., Kovács, G. L., Miseta, A., ... Mühl, D. 2017. Urinary orosomucoid: a novel, early biomarker of sepsis with promising
[59] Ayoya MA, Spiekermann-Brouwer GM, Stoltzfus RJ, Nemeth E, Habicht JP, Ganz T, et al. Alpha 1-acid glycoprotein, hepcidin, C-reactive protein, and serum ferritin are correlated in anemic schoolchildren with Schistosoma haematobium. Am J Clin Nutr 2010;91(6):1784-90

[60] Christiansen, S., Hommel, E., Friberg, L., Mølvig, J., Magid, E., \& Feldt-Rasmussen, B. 2010. Increased urinary orosomucoid excretion is not related to impaired renal function in patients with type 2 diabetes. Journal of Diabetes and Its Complications.2010. 24(1), 28-36.

[61] Christopher. B., Bell, L. N., H. L., R. H., F. K., Mazza, J. J., \& Yale, S. H. (2016). Erythrocyte Sedimentation Rate and C-reactive Protein Measurements and Their Relevance in Clinical Medicine (6th ed., Vol. 115). Gainesville, Florida: WMJ.

[62] Gotts, J. E., \& Matthay, M. A. (2016). Sepsis: pathophysiology and clinical management. BMJ, i1585. 